\title{
ИННОВАЦИИ
}

В ХИМИЧЕСКИХ НАУКАХ

DOI: https://doi.org/10.15688/jvolsu10.2017.2.4

УДК 519.8:678

ББК 32.81

\section{MONTE CARLO SIMULATION OF THE THREE-DIMENSIONAL FREE-RADICAL POLYMERIZATION OF TETRAFUNCTIONAL MONOMERS}

\author{
Yuriy Mikhaylovich Sivergin \\ Doctor of Chemical Sciences, Professor, \\ Institute of Chemical Physics named after N.N. Semenov, RAS \\ library@chph.ras.ru \\ Kosygina St., 4, 119991 Moscow, Russian Federation

\section{Salavat Mudarisovich Usmanov} \\ Doctor of Physical and Mathematical Sciences, Professor, \\ Director of Birsk Branch of Bashkir State University \\ academy@birsk.ru \\ Internatsionalnaya St., 10, 452453 Birsk, Russian Federation

\section{Fanil Rafakovich Gaysin} \\ Candidate of Physical and Mathematical Sciences, Associate Professor, \\ Department of Mathematical Modeling, Information Systems and Economics, \\ Birsk Branch of Bashkir State University \\ academy@birsk.ru \\ Internatsionalnaya St., 10, 452453 Birsk, Russian Federation
}

\section{Aleksandr Lvovich Kovarskiy}

Honored Scientist of the Russian Federation, Doctor of Chemical Sciences, Professor, Head of the Center of Magnetic Spectroscopy,

Institute of Biochemical Physics named after N.M. Emanuel, RAS

library@chph.ras.ru

Kosygina St., 4, 119991 Moscow, Russian Federation 


\begin{abstract}
For the first time in the world practice the results of simulation by Monte Carlo method of the kinetics of three-dimensional free-radical polymerization of tetrafunctional monomers (TFM) have been obtained in the framework of the formation of a unitary threedimensional structural element (UTDSE) and its structure formation on the simple cubic lattice, depending on the length 1 of molecules tetrafunctional monomers $(1=1$ to 40 ribs of the lattice). Peculiarities of kinetics of changes in parameters such as the degree of polymerization of the Pn UTDSE, the number of radicals, the number of cross-links and cycles, and other characteristics are revealed. It is established that UTDSE are characterized by low levels of $\mathrm{Pn}$, and an explanation of this phenomenon is given.
\end{abstract}

Key words: mathematical modeling, Monte Carlo method, polymerization, tetrafunctional monomers, length of molecules.

\section{Introduction}

Kinetics of three-dimensional free-radical polymerization of tetrafunctional monomer (TFM) has been studied superficially using speculative assumptions that caused by complexity of this problem. It is proved that for three-dimensional polymers (TDP) micro-heterogeneous globular morphology is typical [10]. Considering the primary globular (or nanogel) structure of TDP as a unitary three-dimensional structural element (UTDSE) we developed a model of the UTDSE$\mathrm{MC}$ for studying the kinetics of three-dimensional free-radical polymerization of TFM within the framework of formation of UTDSE [6;14].

In works $[6 ; 14]$, we studied this problem mainly using the simple cubic lattices of small dimension (from $3 \times 3 \times 3$ to $10 \times 10 \times 10$ ). The present work is devoted to identify impact of TFM molecules length $l$ in a wide range of $l(l=1$ to 40 ribs of the lattice). Experimental investigation of the kinetics of a block of free-radical polymerization of oligoesteracrylates (OEA) with oligomeric block of varying length revealed the influence of the block length on the gross kinetics of polymerization of OEA $[1 ; 13]$. The authors obtained the kinetic curves of the degree of conversion of OEA and the reaction rate, the position of which were changed by varying the length of the oligomeric block in the direction of acceleration of the process of polymerization. These regularities were explained by the increase of viscosity of the reaction media (viscosity increases with the length of OEA molecules) as well as by the ratio of the rate constants of propagation and termination of chains $[1 ; 13]$.

There are no literature data for the study of kinetics of three-dimensional free-radical polymerization of polyfunctional monomers within the framework of forming a unitary threedimensional structural element (UTDSE) except our works $[4 ; 6 ; 14]$. The reason is the lack of experimental equipment with the necessary sensitivity which would enable to solve the problem.

In this paper we analyze the impact of the length of tetrafunctional monomers molecules (TFM) on the kinetics of formation of UTDSE, which is the primary structural element (nanogel) macrobody in a three-dimensional polymer (TDP) [10]. According to the offered scheme of structure formation of macrobodies of TDP, this process is realized in the following order: monomer (oligomer $\rightarrow$ nanogel(UTDSE) $\rightarrow$ microgel (many of the UTDSE) $\rightarrow$ macrobody TDP (multitude of microgels).

In works $[4 ; 6]$ a detailed analysis of the literature data related to the problem of the kinetics of three-dimensional free-radical polymerization of polyfunctional monomers was performed, including a clear distinction between processes of structurization from the positions of percolation in conditions of physical and chemical structure formation. The analysis frees us from the need to perform the literature review in this work.

\section{Setting up a problem and the experimental part}

Modeling of three-dimensional free-radical polymerization TFM carried out by the statistical Monte Carlo (MC) method using the simple cubic lattice with the dimensions $40 \times 40 \times 40$ with inert walls. One of the double bonds (randomly selected) of TFM was positioned and then initiated 
on the lattice molecule (M). In the framework of formation of UTDSE initiation reaction of the double bond $\mathrm{M}$ is implemented only once - at the time of the initial act of chain initiating.

At the subsequent stages double bonds of PG in the side groups of chains are initiated (we denote the share of these groups by $D$ ). The reactivity of double bonds in $\mathrm{M}$ and $\mathrm{PG}$ is the same $[11 ; 12]$. When modeling we took into account the reactions of initiation:

$$
\begin{gathered}
v_{i}=k_{i}\left[R_{0}\right][M], \\
v_{i}^{\prime}=k_{i}\left[R_{0}\right][P G] .
\end{gathered}
$$

After initiation the reactions of chain propagation

$$
\begin{aligned}
v_{p} & =k_{p}[R][M], \\
v_{p}^{\prime} & =k_{p}^{\prime}\left[R^{\prime}\right][M]
\end{aligned}
$$

and termination become possible

$$
\begin{gathered}
v_{t}=k_{t}[R]^{2}, \\
v^{\prime}{ }_{t}=k_{t}[R]\left[R^{\prime}\right], \\
v^{\prime \prime}{ }_{t}=k_{t}\left[R^{\prime}\right]^{2},
\end{gathered}
$$

where $R$ is radical in the form of pendant; $R^{\prime}$ - active radical of A type characterized by the less reactivity compared to $R$ due to the greater steric difficulties in $R^{\prime}$; it is assumed for it that $k_{p}^{\prime}=0.1 k_{\mathrm{p}}$. In these equations $v_{i}, v_{i}^{\prime}, v_{p}, v_{p}^{\prime}, v_{t}, v_{t}^{\prime}, v_{t}^{\prime \prime}{ }_{t}$ and $k_{i}, k_{p}, k_{p}^{\prime}, k_{t}$ - the rates and rate constants of the reactions of initiation, propagation, and termination of the chain; $R_{\mathrm{o}}$ - primary initiating radical, that in the reactions of chain termination is not involved, as in this case, the model does not work.

In the process of implementing a threedimensional polymerization of TFM, reactions of chain cross-linking (7-11) and the cycles formation (12-16) occur by mechanisms for $R$ $P G, R^{\prime}-P G, R-R, R-R^{\prime}$ and $R^{\prime}-R^{\prime}$ :

$$
\begin{gathered}
v_{c r}=k_{c r}[R][P G], \\
v_{c r}^{\prime}=k_{c r}^{\prime}\left[R^{\prime}\right][P G], \\
v_{t c r}=k_{t c r}[R]^{2}, \\
v_{t c r}^{\prime}=k_{t c r}[R]\left[R^{\prime}\right], \\
v^{\prime \prime}{ }_{t c r}=k_{t c r}\left[R^{\prime}\right]^{2}, \\
v_{c y}=k_{c y}[R][P G],
\end{gathered}
$$

$$
\begin{gathered}
v_{c y}^{\prime}=k_{c y}^{\prime}\left[R^{\prime}\right][P G], \\
v_{t c y}=k_{t c y}[R]^{2}, \\
v_{t c y}^{\prime}=k_{t c y}[R]\left[R^{\prime}\right], \\
v^{\prime \prime}{ }_{t c y}=k_{t c y}\left[R^{\prime}\right]^{2},
\end{gathered}
$$

here: $v_{c r^{\prime}}, v_{c r^{\prime}}^{\prime} v_{t c r}, v_{t c r}^{\prime}, v_{t c r^{\prime}}^{\prime \prime} v_{c y^{\prime}}, v_{c y^{\prime}}^{\prime}, v_{t c y^{\prime}} v_{t c y}^{\prime}, v_{t c y}^{\prime \prime}$ are the rates of chain cross-linking and the cycles formation, $k_{c r}, k_{c r}^{\prime}, k_{t c r}, k_{c y}, k_{c y}^{\prime}, k_{t c y}$ are the rate constants of these reactions. As the reactivity of double bonds in $\mathrm{M}$ and PG equal and the equality of reaction constant rates was accepted $k_{c r}=k_{c y}=k_{p}, k_{c r}^{\prime}=k_{c y}^{\prime}=k_{p}^{\prime}$, reactions (7, $8,12,13)$ are among reactions $(2,3)$; in view of the equality of reactivity of radicals $R$ and $R^{\prime}$ in reactions (4-6) and in (9-11, 14-16) and equality of the rate constants of reactions $k_{t c r}=k_{t c y}=k_{t}$, reactions (9-11, 14-16) are included in the reactions (4-6). The possibility of occurrence of this or that elementary reaction of the above mentioned will depend on the probability of encounters (contact) of appropriate reactive centers.

For the above reasons, in the calculation of the probability reactions $p_{i}$ we took into account only six elementary stages $j=\overline{1 . .6}$. At each stage of modeling one needs to identify which of these six reactions will run. The stage number $j$ $(j=\overline{1 . .6})$ is found from the condition:

$$
\sum_{i=1}^{j-1} p_{i}<\xi_{1}<\sum_{i=1}^{i=j} p_{i}
$$

where $p_{i}=\frac{V_{i}}{\sum_{i=1}^{n} V_{i}}$ is the probability of occurrence of the $i$-th elementary stage (or $p_{i}$ is the statistical weight of the $i$-th reactions); designating by the $V_{i}$ - the rate of $i$ the reaction one can obtain $V=\Sigma V_{i}=v_{i}+v_{p}+v_{p}^{\prime}+v_{t}+$ $+v_{t}^{\prime}+v^{\prime \prime}{ }_{t}$; total probability $P=\Sigma p_{i}=1$.

Waiting time of specific elementary stage of polymerization is found from the relation:

$$
\tau_{k}=\frac{-\ln \xi_{2}}{\sum_{i=1}^{6} V_{i}}
$$

here $\xi_{1}$ и $\xi_{2}$ - are random numbers uniformly distributed in the interval $(0,1)$. In the product $t k_{p}$ the parameter $k_{p}$ is the constant rate of pseudofirst order of chain propagation. A total polymerization time $\left(T_{p o l}\right)$ is determined by the sum of waiting time for all stages

$$
T_{p o l}=\sum \tau_{k}
$$


In the initial stages of three-dimensional polymerization of TFM is a purely stochastic process (selection of possible reaction, etc.), but from a certain degree of conservation $(G)$ an element of determinism interferes and its contribution increases with the growth of $G$ with the transition to the final stages of the process primarily in deterministic mode.

In addition to the reactions of quadratic termination of the radicals $R$ and $R^{\prime}$, there is linear radicals termination in reaction system with their immobilization (automatically considered as residual radicals $R$ and $R^{\prime}$ ):

$$
\begin{aligned}
R+Y \rightarrow R Y & v_{t l}=k_{t l}[R][Y], \\
R^{\prime}+Y \rightarrow R^{\prime} Y & v_{t l}^{\prime}=k_{t l}^{\prime}\left[R^{\prime}\right][Y],
\end{aligned}
$$

where $v_{t l}, v_{t l}^{\prime}, k_{t t}, k_{t l}^{\prime}$ - the rates and rate constants of linear termination of radicals.

From the reaction schemes it is clear that the growth of the molecular mass of UTDSE frame is performed only by the reactions of chain propagation $(2,3)$. Reactions of cross-linking and cycle formation do not lead to growth of molecular mass of UTDSE, and cause only topological changes in the frame of UTDSE macroradical cross-linking between each other, as well as the formation of cyclic structures of different sizes. The process was conducted before the possibility of a reaction proceeding (exhaustion of available double bonds, and so on). Re-visiting the nodes was forbidden (selfintersections are absent).

When modeling of TFM polymerization by MC method at every stage of the simulation we randomly determined the choice of elementary reactions (random choice of conditions in which the reaction system will convert), its direction, location of TFM molecule, the choice of functional group, the waiting time of transition [4].

The following values for the rate constants of reactions were adopted: $k_{i}=k_{p}=400 \mathrm{l} / \mathrm{mol} \cdot \mathrm{c}$, $k_{t}=10^{6} \mathrm{l} / \mathrm{mol} \cdot \mathrm{c}, k_{p}^{\prime}=40 \mathrm{l} / \mathrm{mol} \cdot \mathrm{c}$. The length $l$ of TFM molecules varied in a range from 1 to 40 ribs ( 2 to 41 nodes). If you take the density of TFM equal to $1.05 \mathrm{~g} / \mathrm{ml}$ and the molar mass to $200 \mathrm{~g} / \mathrm{mol}$, the simulated volume for this lattice and TFM molecule with $l=2$ ribs is $13179 \mathrm{~nm}^{3}$ (the lattice $40^{3}$ consist of 21333 this monomer molecules).
Accordingly, for monomers with another length $l$ this reaction volume will be different for the same amount of monomer, as well as the reaction volume was adopted constant, then different number of monomer molecules (from 32,000 at $l=1$ to 1560 monomer molecules at $l=40$ ). Averaging of obtaining parameters to the current moment of time we spent 5000 experimental implementations; it is clear that every experiment did not depend on others.

\section{Results and Discussion}

The kinetic curves of free-radical polymerization of TFM in coordinates: the degree of polymerization $P_{n}$ - time $t k_{p}$ (Fig. 1) have the form of sigma-shaped curves (except the case of TFM with $l=1$, for which the process is not managed to grow by average values $P_{n}$ up to high values of $P_{n}$ ), to be the exact form of the experimental curve $G(t)$ obtained in the case of block polymerization OEA [1; 13]. Quantitatively limit values $P_{n}$ decrease in the row: $l=2 \rightarrow 40$, which is quite natural and expected, because at the same row reduces the number of molecules that located in a given constant volume of the reaction (Table 1, Fig. 1). At appropriate $G$ values curves $P_{n}(t)$ to some extent shifted towards shorter times with the elongation of TFM molecules, which is in agreement with experiment for the case of block polymerization of OEA $[1 ; 13]$. This result is predictable, if you put the emerging UTDSE is a nano-reactor in which the polymerization of TFM realized. In the regime of block polymerization of TFM there are numerous nano-reactors, located in the reaction volume.

The essential difference between the curve $P_{n}(t)$ for monomer with $l=1 \mathrm{rib}$ is due to the fact that such a short-chained monomer is characterized by a high probability to cycle formation arising in the process of polymerization. Due to the presence of a high share of cyclic structures when the number of parallel experiments is 5000 the averaging of parameters causes the observed shape of the curve $P_{n}(t)$ for this monomer (Fig. 1, curve 1). Of course, among 5000 structures UTDSE at $l=1$ one can find UTDSE with high values of $P_{n} \approx 23665-23840$, but the share of such UTDSE, as will be shown below, significantly less than the share of UTDSE with low values of $P_{n}$. 


\section{ИННОВАЦИИ В ХИМИЧЕСКИХ НАУКАХ}
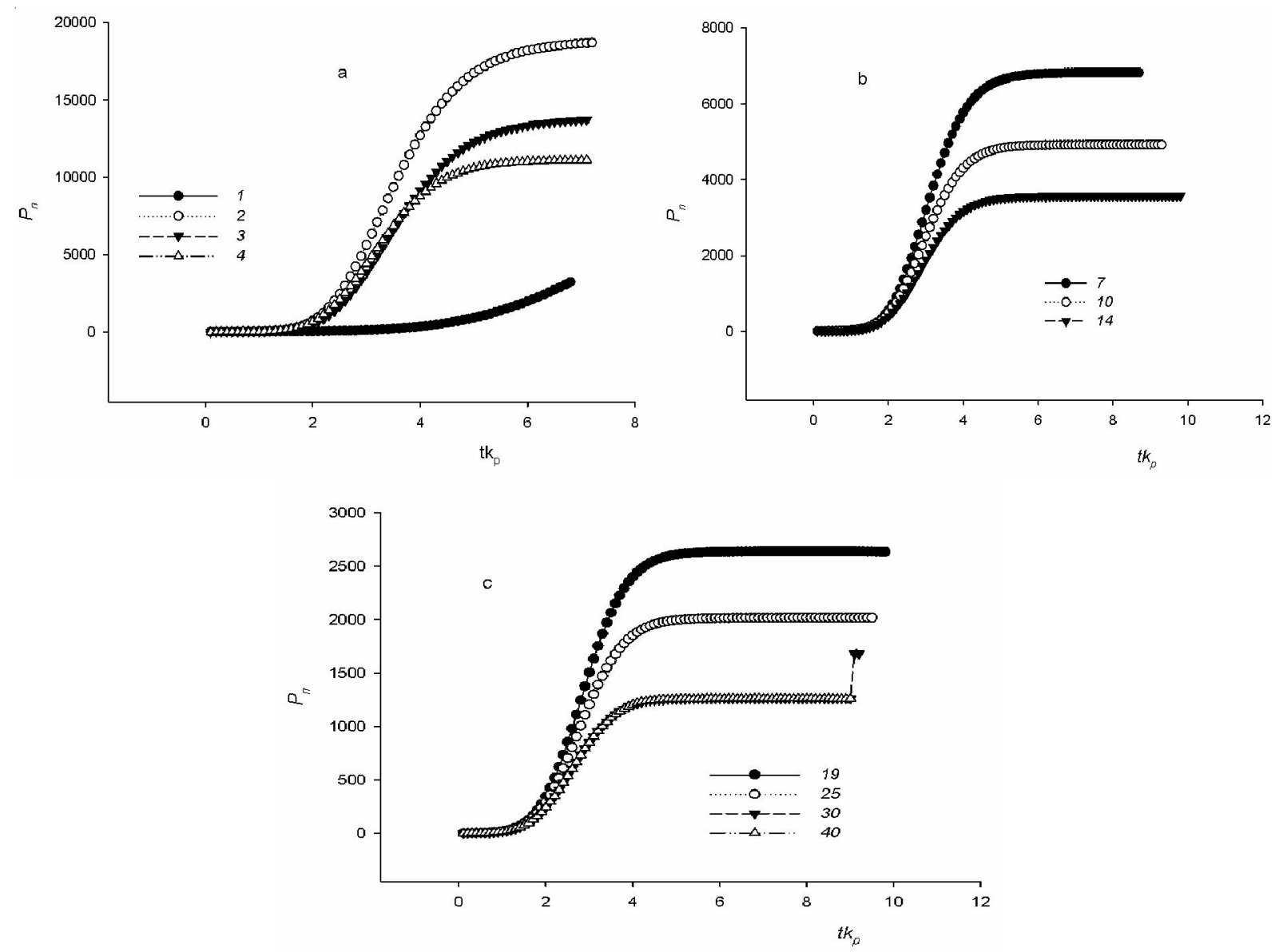

Fig. 1. Kinetic dependence of the degree of polymerization UTDSE at different length $l$ (in the ribs of the lattice, numbers in front bracket) for TFM molecules: $a-1$ (1), 2 (2), 3 (3), 4 (4); $b-7$ (1), 10 (2), 14 (3); c- 19 (1), 25 (2), 30 (3), 40 (4)

\section{Limit values of kinetic parameters at different lengths $\boldsymbol{l}$ of TFM molecules}

Table 1

\begin{tabular}{|c|r|r|r|r|r|r|r|r|}
\hline $\begin{array}{c}l, \text { Number } \\
\text { of grids }\end{array}$ & \multicolumn{1}{c|}{$P_{n}$} & $N_{R}$ & \multicolumn{1}{c|}{$N_{R^{\prime}}$} & $N_{R}+N_{R^{\prime}}$ & $N_{R^{\prime}} / N_{R^{\prime}}$ & \multicolumn{1}{c|}{$D$} & $N_{P G}$ & $k_{\text {pack }}$ \\
\hline 1 & 3226 & 124 & 129 & 253 & 0.96 & 0.124 & 457 & 0.25 \\
2 & 18696 & 3580 & 491 & 4071 & 7.3 & 0.012 & 227 & 0.786 \\
3 & 13716 & 3568 & 464 & 4032 & 7.69 & 0.018 & 251 & 0.765 \\
4 & 11119 & 3884 & 320 & 4204 & 12.1 & 0.009 & 107 & 0.822 \\
7 & 6818 & 3556 & 186 & 3742 & 19.1 & 0.004 & 24 & 0.837 \\
10 & 4919 & 3116 & 109 & 3225 & 28.6 & 0.0008 & 4 & 0.836 \\
14 & 3565 & 2574 & 66 & 2640 & 39 & 0.0006 & 2 & 0.831 \\
19 & 2637 & 2073 & 40 & 2113 & 51.8 & 0.003 & 6.9 & 0.825 \\
25 & 2019 & 1686 & 25 & 1711 & 67.4 & 0.001 & 2 & 0.81 \\
30 & 1684 & 1451 & 18 & 1469 & 80.6 & 0.001 & 1.9 & 0.808 \\
40 & 1262 & 1130 & 9.4 & 1139.4 & 120.2 & 0.001 & 1.3 & 0.773 \\
\hline
\end{tabular}

As we can see from Table 1, the difference between the $P_{n}$ for monomers with $l=2$ and $l=$ 40 reaches 15.5 , but by the values of achieved molar mass $m$ UTDSE this difference is significantly less: the ratio $m_{l=2} / m_{l=40}=0.75$, and for the whole range of lengths $l$ the value of the ratio $m_{l=2} / m_{l}$ varies from 0.91 to 0.74 , falling down with increasing of $l$.

Equations $(22-22 b)$ allow to estimate the importance of the limit value of polymerization 
degree of UTDSE $P_{n}$ at the desired length and conditions under consideration of the threedimensional polymerization of TFM:

$$
\begin{gathered}
P_{n}=30925 \cdot \exp (-0.026 l)(l=2 \div 4),(22) \\
P_{n}=12735 \cdot \exp (-0.092 l)(l=7 \div 14),(22 \mathrm{a}) \\
P_{n}=7215 \cdot \exp (-0.051 l)(l=14 \div 25),(22 \mathrm{~b}) \\
P_{n}=4335 \cdot \exp (-0.031 l)(l \geq 25) . \quad(22 \mathrm{c})
\end{gathered}
$$

The change in the number of radicals $N_{R}$ and $N_{R^{\prime}}$ in the course of polymerization process of TFM illustrated in Fig. 2: the number of radicals $N_{R}$ decreases in a row TFM with $l=4>$ $2>3>7>10>14>19>25>30>40>1$, and for change of the number of radicals $N_{R^{\prime}}$ we got the dependence of the $l$ type: $l=2>3>4>$ $7>1>10>14>19>25>30>40$. Limit values of numbers $N_{R}$ and $N_{R^{\prime}}$ fit in the same dependence, and the dependence of the sum of the limit values $\left(N_{R}+N_{R^{\prime}}\right)$ is similar to the dependence of $N_{R}$ from $l$ (Table 1). Except the variation of $l=1$, all dependencies $N_{R}(t)$ have the form of sigma shaped curves. The curves $N_{R}{ }^{\prime}(t)$ have similar character, but expressed less clear for $l=2,3,4,7$ (Fig. 2). Out of these regularities is the case for TFM with $l=1$. The number of $N_{R}$ in this version is significantly less compared with other $l$ and the number $N_{R^{\prime}}$, were almost equal to $N_{R}$, less when $l=2$ to 7 , but more than at $l>10$ (Fig. 2, Table 1). The dependences of limited values of $N_{R}$ and $N_{R^{\prime}}$ on $l$ are described by exponential functions (23) and (24) allowing to assess the magnitude of $N_{R}$ and $N_{R^{\prime}}$, for other values of $l$. Functions converge at a limit $\rightarrow 0$ :

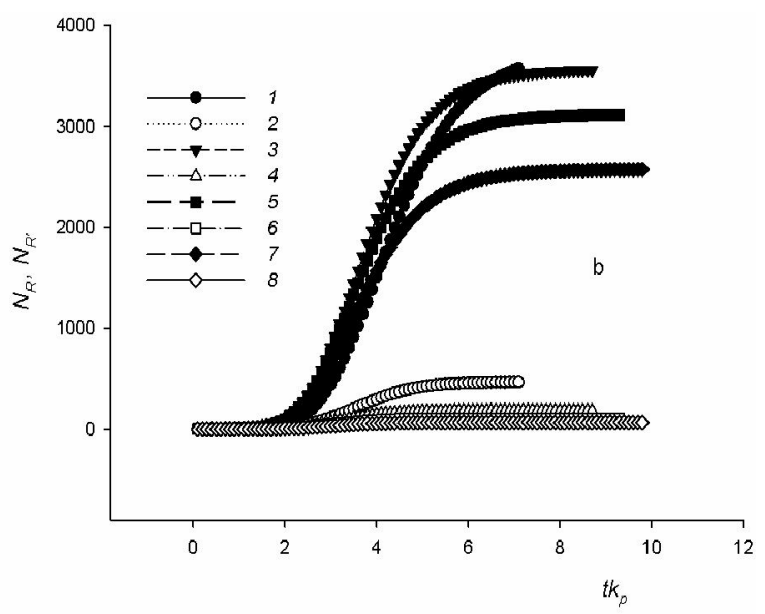

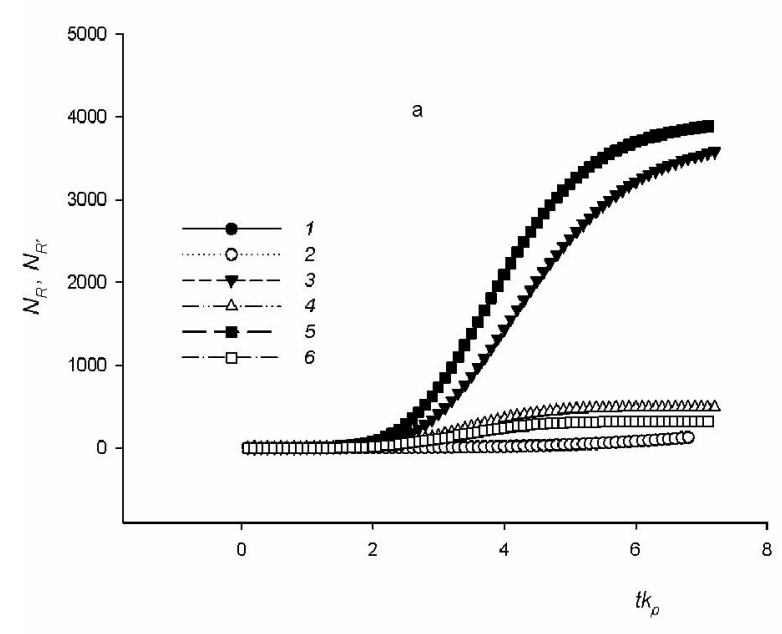

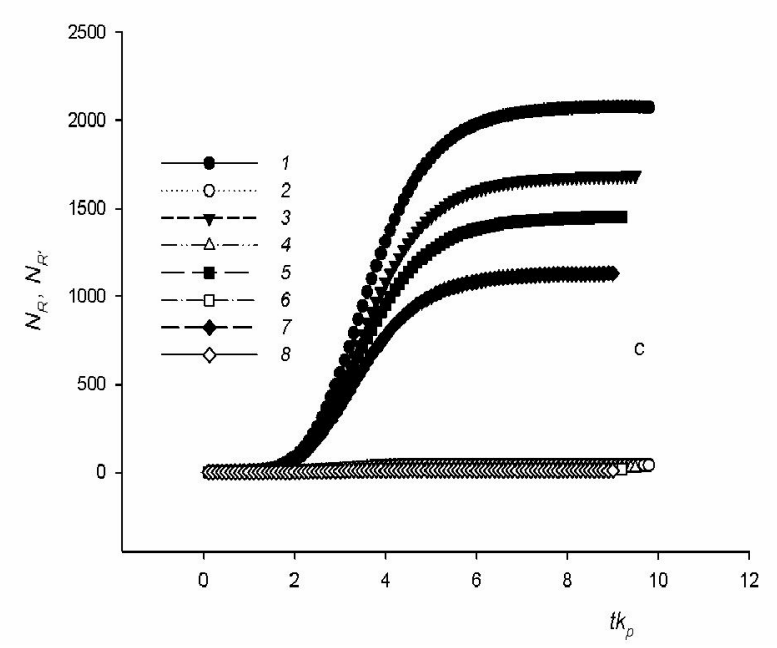

Fig. 2. The change in the number of radicals $N_{R}(1,3,5,7)$ и $N_{R^{\prime}}(2,4,6,8)$ with time for UTDSE, obtained at: $a-l=1(1,2), 2(3,4), 4(5,6) ; b-l=3(1,2), 7(3,4), 10(5,6), 14(7,8) ; c-l=19(1,2), 25(3,4), 30(5,6), 40(7,8)$ 


$$
\begin{aligned}
& N_{R}=4715 \cdot \exp (-0.043 l)(l=4 \div 22), \quad(23) \\
& N_{R}=3240 \cdot \exp (-0.026 l)(l=22 \div 40),(23 \mathrm{a}) \\
& N_{R^{\prime}}=750 \cdot \exp (-0.195 l)(l=2 \div 11), \quad(24) \\
& N_{R^{\prime}}=210 \cdot \exp (-0.084 l)(l=12 \div 40) .(24 \mathrm{a})
\end{aligned}
$$

From dependencies $N_{R}$ of and $N_{R^{\prime}}$ it follows that the rate of change of radicals in the process of three-dimensional free-radical polymerization of TFM are not equal to zero, $i$. e. to use the approach of steady-state condition of the process relative to the radicals in this case, is unauthorized. This conclusion is very useful and should be taken into account in the analysis of experimental kinetic study of TFM polymerization $[1 ; 13]$. From the relations of the limit values of $N_{R} / N_{R^{\prime}}$ (Table 1) it is clear that with increasing $l$ this attitude increases, $i$. e., with increasing the length of TFM molecules the number of generated radicals of $R$ ' type falls, due to decrease of the contribution of the shares of the process of cycle formation with increasing of $l$.

In all cases for $l$ the number of cross-links $N_{c r}$ exceeds the number of cycles $N_{c y}\left(N_{c r}>N_{c y}\right)$, and in a series of increasing $l$, as earlier, from the patterns of growth in the $N_{c r}$ and $N_{c y}$ with the rise of $l$ the case $l=1$ drops out (Fig. 3, Table 2). As it was expected, with increasing of $l$ the contribution of cycle formation process should decrease, that we observe in the example of the relationship $N_{c r} / N_{c y}$.

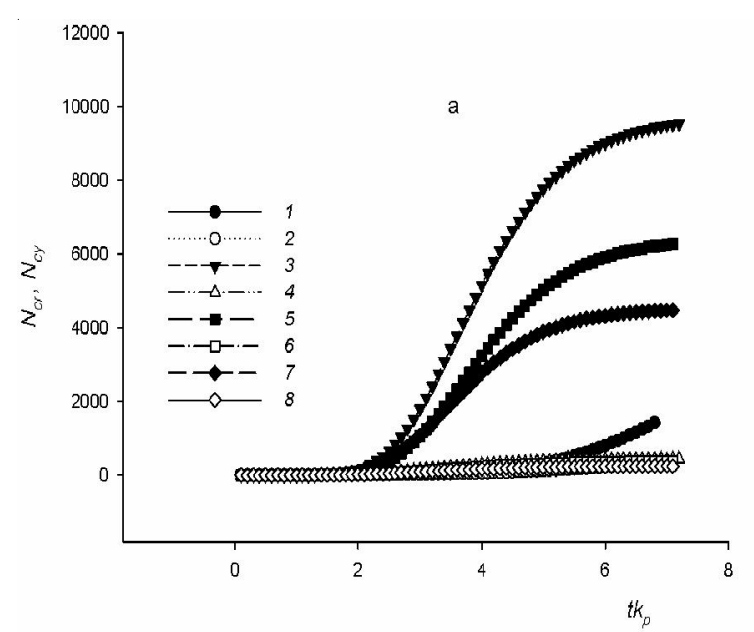

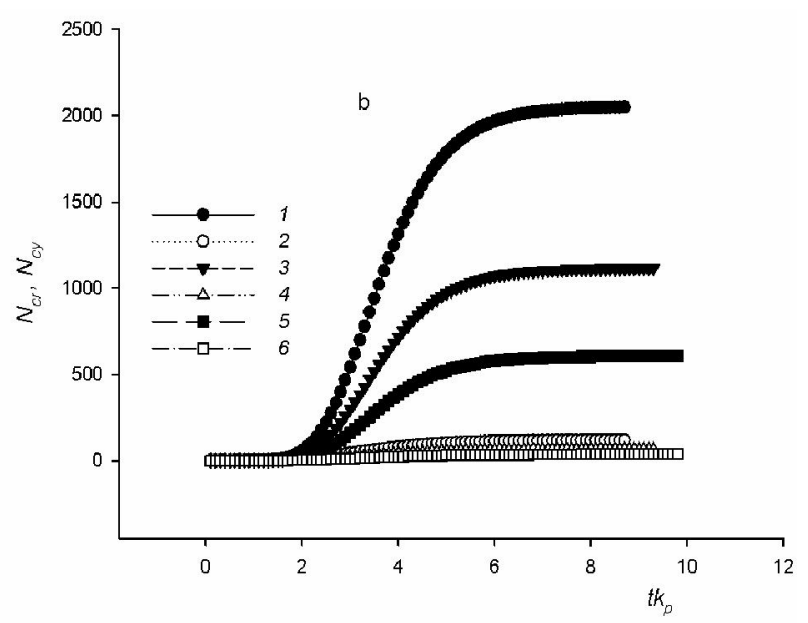

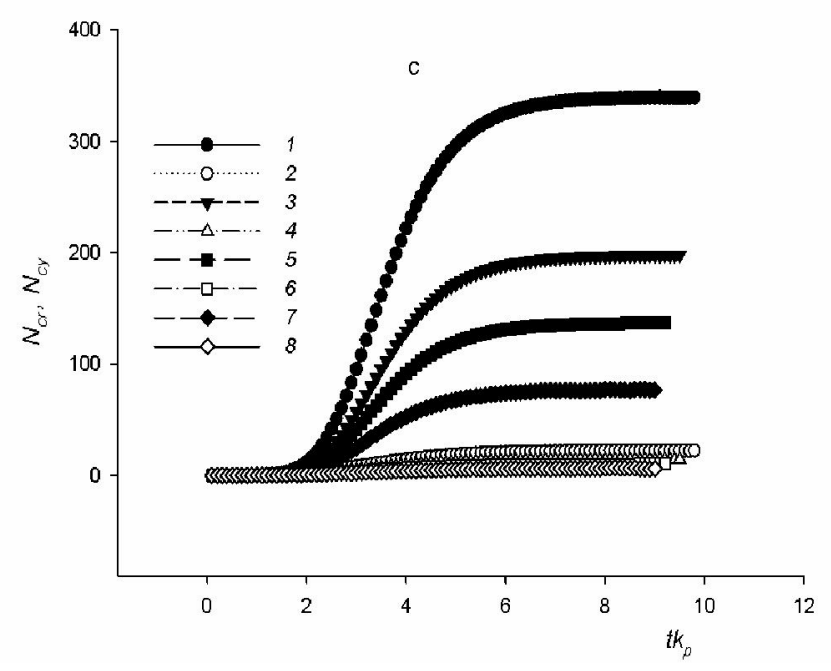

Fig. 3. The dependence of the number of cross-links $N_{c r}(1,3,5,7)$ and the number of cycles $\mathrm{N}_{\mathrm{cy}}(2,4,6,8)$ on time for UTDSE obtained at:

$a-l=1(1,2), 2(3,4), 3(5,6), 4(7,8) ; b-l=7(1,2), 10(3,4), 14(5,6) ; c-l=19(1,2), 25(3,4), 30(5,6), 40(7,8)$ 
Limit values of $N_{c r}$ and $N_{c y}$, the amount of cycles $\left(N_{c r}+N_{c y}\right)$, relations $\left(N_{c r} / N_{c y}\right)$ and the number of reactions $R-P G, R^{\prime}-P G, R-R, R-R^{\prime}, R^{\prime}-R^{\prime}$ at different lengths $\boldsymbol{l}$ of TFM molecules

\begin{tabular}{|c|c|c|c|c|c|c|c|c|c|}
\hline $\begin{array}{c}l, \text { Number } \\
\text { of grids }\end{array}$ & $N_{c r}$ & $N_{c y}$ & $N_{c r}+N_{c y}$ & $N_{c r} / N_{c y}$ & $N_{R-P G}$ & $N_{R^{\prime}-P G}$ & $N_{R-R}$ & $N_{R-R^{\prime}}$ & $N_{R^{\prime}-R^{\prime}}$ \\
\hline 1 & 1421 & 313 & 1734 & 4.54 & 1133 & 74 & 188 & 219 & 120 \\
2 & 9542 & 451 & 9993 & 21.16 & 5208 & 602 & 2046 & 1338 & 799 \\
3 & 6278 & 382 & 6660 & 16.43 & 3670 & 376 & 1561 & 604 & 449 \\
4 & 4482 & 250 & 4732 & 17.93 & 2472 & 282 & 1356 & 314 & 308 \\
7 & 2048 & 118 & 2166 & 17.4 & 1185 & 100 & 711 & 69 & 101 \\
10 & 1115 & 64 & 1179 & 17.42 & 629 & 43 & 441 & 24 & 42 \\
14 & 605 & 37 & 642 & 16.35 & 344 & 17 & 256 & 9.0 & 16 \\
19 & 339 & 22 & 361 & 15.41 & 198 & 7 & 146 & 3.6 & 6.4 \\
25 & 198 & 14 & 212 & 14.14 & 116 & 3 & 89 & 1.6 & 2.4 \\
30 & 137 & 10 & 147 & 13.7 & 78 & 1.9 & 64.4 & 1.1 & 1.6 \\
40 & 77 & 6 & 83 & 12.83 & 43 & 1 & 38 & 0.4 & 0.6 \\
\hline
\end{tabular}

It is known that with chain elongation the probability of encounters of two ends of this chain in any micro-volume decreases. For molecules of TFM with $l=1$, the probability of two ends of this molecule encounters is equal to zero, but in the course of polymerization process there are situations when the two ends of the growing macro-chain come into contact with each other, causing a cycle that is facilitated by the high probability of the reaction of chain termination at radicals contact. These situations arise often when $l=1$, as evidenced by achieving $N c y \sim 950-1050$ in a hypothetical variant of the achievement of $k_{\text {pack }} \sim 0.76-0.83$ for TFM with $l=1$.

As one can see, $N_{c y}$ was the greatest (case 1) at $l=1$, indicating a very significant private contribution to the process of cycle formation for this variant of TFM. This case probably extends to other TFM which molecules longer that $l=1$, but they are also hard (simbat to $l=1$ ), excluding the possibility of encounters of macromolecule ends, and yet the share of process of cycle formation can be very significant for them in the course of construction of UTDSE for the reasons mentioned for molecule with $l=1$.

The comparison of the number of $N_{c y}$ per 100 units of UTDSE (cases III and IV) also confirms the highest probability of cycle formation for TFM with $l=1$ (calculation of $N_{c y}$ made on the basis of average (5000 experiments) values of $N_{c y}$ both with the value of $N_{c y}$ for a single UTDSE). Assessing the number of cycles $N_{c y}$ for these different options may be carried out using the following equations:
I. UTDSE with the averaged $P_{n}$

$$
\begin{gathered}
N_{c y}=737 \cdot \exp (-0.251 l)(l=2 \div 7), \quad(25) \\
N_{c y}=123 \cdot \exp (-0.088 l)(l=10 \div 19),(25 \mathrm{a}) \\
N_{c y}=55 \cdot \exp (-0.056 l)(l \geq 25) . \quad(25 \mathrm{~b})
\end{gathered}
$$

II. Single UTDSE with the maximal value $P_{n}$

$$
\begin{gathered}
N_{c y}=910 \cdot \exp (-0.271 l)(l=2 \div 10), \quad(26) \\
N_{c y}=230 \cdot \exp (-0.133 l)(l=10 \div 19),(26 \mathrm{a}) \\
N_{c y}=42 \cdot \exp (-0.041 l)(l \geq 19) . \quad(26 \mathrm{~b})
\end{gathered}
$$
UTDSE)

III. Per 100 units of UTDSE (averaged

$$
\begin{aligned}
& N_{c y}=3.15 \cdot \exp (-0.082 l)(l=2 \div 14) \\
& N_{c y}=1.52 \cdot \exp (-0.03 l)(l=14 \div 40)
\end{aligned}
$$

IV. Per 100 units (single UTDSE with maximal value of $P_{n}$ )

$$
\begin{gathered}
N_{c y}=3.5 \cdot \exp (-0.09 l)(l=2 \div 19), \\
N_{c y}=0.92 \cdot \exp (-0.008 l)(l \geq 19) .
\end{gathered}
$$

In the equations of the form $N_{c y}=N_{0 c y} \cdot \exp$ $(-\Delta \cdot l)$ preexponential factor $N_{0 c y}$ indicates the number of cycles for chains with self-intersection, and the coefficient $\Delta$ is the variations of cycles in real chain.

Dependence $N_{c y}(l)$ is shown in Fig. 4 for options I and III, IV. It gives vivid example about 
this dependence. Experimental verification of the number of cycles in a three-dimensional polymer is rather scanty and executed, for example, for diallyl derivatives of dicarboxylic acids [7-9]. The changes were revealed in the number of cycles for polymers of diallyl sebacinate (DAS) $\left(N_{c y}=\right.$ 3.8-26.9 for fractions of pre-gel stage with $P_{n}=$ 28.4-191, when $\left.P_{n}=100 N_{c v}=10-18\right)$ and for diallyl isophtalate (DAIPh) $\left(N_{c y}=2.7-68.4\right.$ for fractions pre-gel stage with $P_{n}=7-407$, when $\left.P_{n}=100 N_{c y}=16-34\right)$. During polymerization of diallyl derivatives great contribution to the formation of structural units makes the reaction of chain transfer to monomer, including influencing the process of cycle formation. The length of the DAS molecule is greater than the length of the $\mathrm{DAIPh}$ molecule, that determines the increase in the number of cycles in DAIPh macro-chain. These results correlate with the regularities which we established in this work and that testifies in favor of a model of the UTDSE-MC, developed by us. Earlier $[6 ; 8]$ we have shown that the process of cycle formation in the threedimensional polymerization of TFM affects the rate of initiation of the chain, the size of reaction volume $(V)$, the geometry of lattices (g.l. or reaction volume), the activity of reactor walls (arw.), the chemical nature of TFM (c.n.). In this work we have established the influence of the length of molecules TFM on this process. Thus, one can write that $N_{c y}=f\left(v_{i}, V, g . l .\right.$, a.w., c.n., $\left.l\right)$.

The variation of the number of cycles $N_{c y}$ per 100 units of UTDSE has a drop-down type with $l$ rising and that is to be expected (the reaction

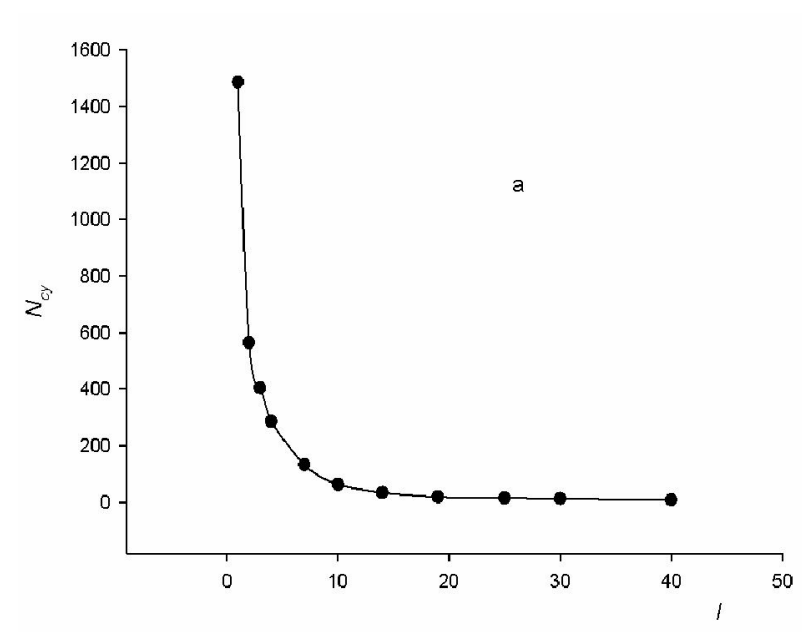

volume is constant, and $l$ is growing). An estimate of the number of $N_{c y} 100$ units of UTDSE allow one to sign the expressions:

V. per 100 units of UTDSE (averaged UTDSE)

$$
\begin{gathered}
N_{c r}=61.6 \cdot \exp (-0.1 l)(l=2 \div 14), \\
N_{c r}=27.5 \cdot \exp (-0.04 l)(l=14-40) .
\end{gathered}
$$

VI. per 100 units of UTDSE (single UTDSE with maximal $P_{n}$ )

$$
\begin{aligned}
& N_{c r}=62.6 \cdot \exp (-0.104 l)(l=1 \div 14),(30) \\
& N_{c r}=29.7 \cdot \exp (-0.043 l)(l=14-40),(30 \mathrm{a}) \\
& N_{c r}=49.7 \cdot \exp (-0.062 l)(l=1-40) .(30 \mathrm{~b})
\end{aligned}
$$

In all cases, the correlation coefficient $r=0.98-0.999$. In expressions (29) and (30), (29a) and (30a) the values of numerical coefficients close to each other, preexponential factor $N_{0 c r}$ is the number of cross-linking in the case of chains with self-intersection, and coefficient $\Delta$ is a change in the number of crosslinking in a real chain. Equation (30b) illustrates the admissibility of the use of more general function for $l=(1-40)$. In [7-9] it was estimated the number of branching points in chains of prepolymers of diallyl derivatives. Because each crosslink has two branch points, for cases V and VI we shall receive from 10 to 116 branching points in a row $l=1-40$, which significantly exceeds the number of branch points (6-7) to pre-polymers diallyl derivatives, but this fact should not come as a surprise, because in the latter case considered pregel

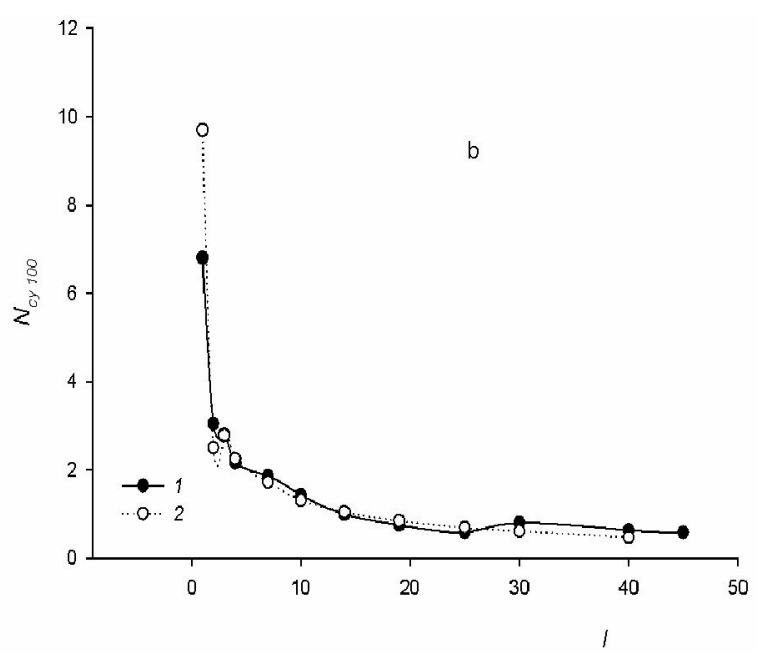

Fig. 4. Changing number of cycles $N_{c y}$ with elongation of TFM molecules for options II $(a)$ and III, IV $(b)$ 


\section{ИННОВАЦИИ В ХИМИЧЕСКИХ НАУКАХ}

stage, the reactions of chain transfer and other. In a series with $l=(2 \rightarrow 40)$ the number of cross-links regularly decreases, as well as the attitude $N_{c r} / N_{c y}$, and the number of cross-links significantly greater than the value $N_{c y}$ (Table 2, Fig. 3). The dependence $N_{c y}$ on $P_{n}$ is predominantly linear, and dependence of $N_{c r}$ on $P_{n}$ - is an nonlinear increasing curve [4].
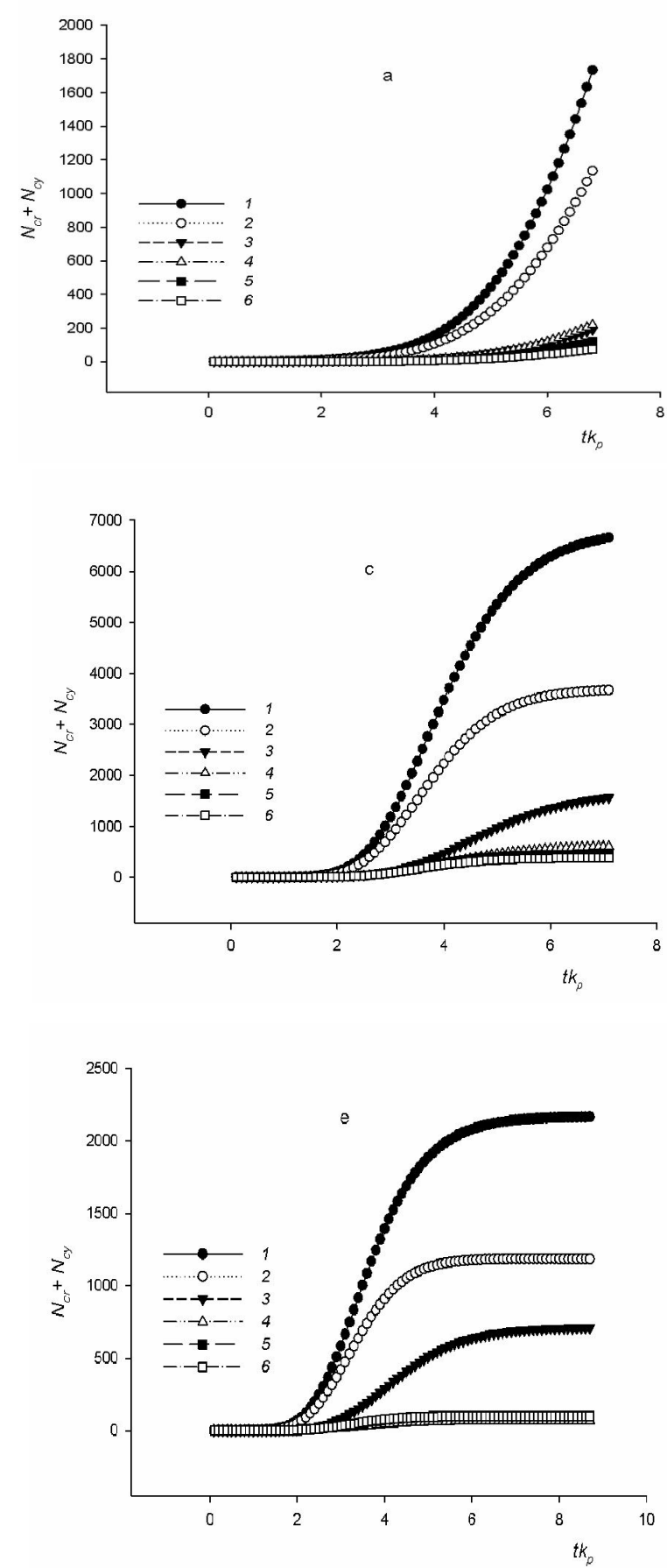

The processes of cross-linking and cycle formation during three-dimensional polymerization of TFM include reactions $R-P G, R^{\prime}-P G, R-R, R-R^{\prime}$ and $R^{\prime}-R^{\prime}$. The ratio of the contributions of these reactions in the cross-linking of macro-chains and cycle formation is clear from Table 2 and Fig. 5, i. e. the main share of these reactions is cross-linking.
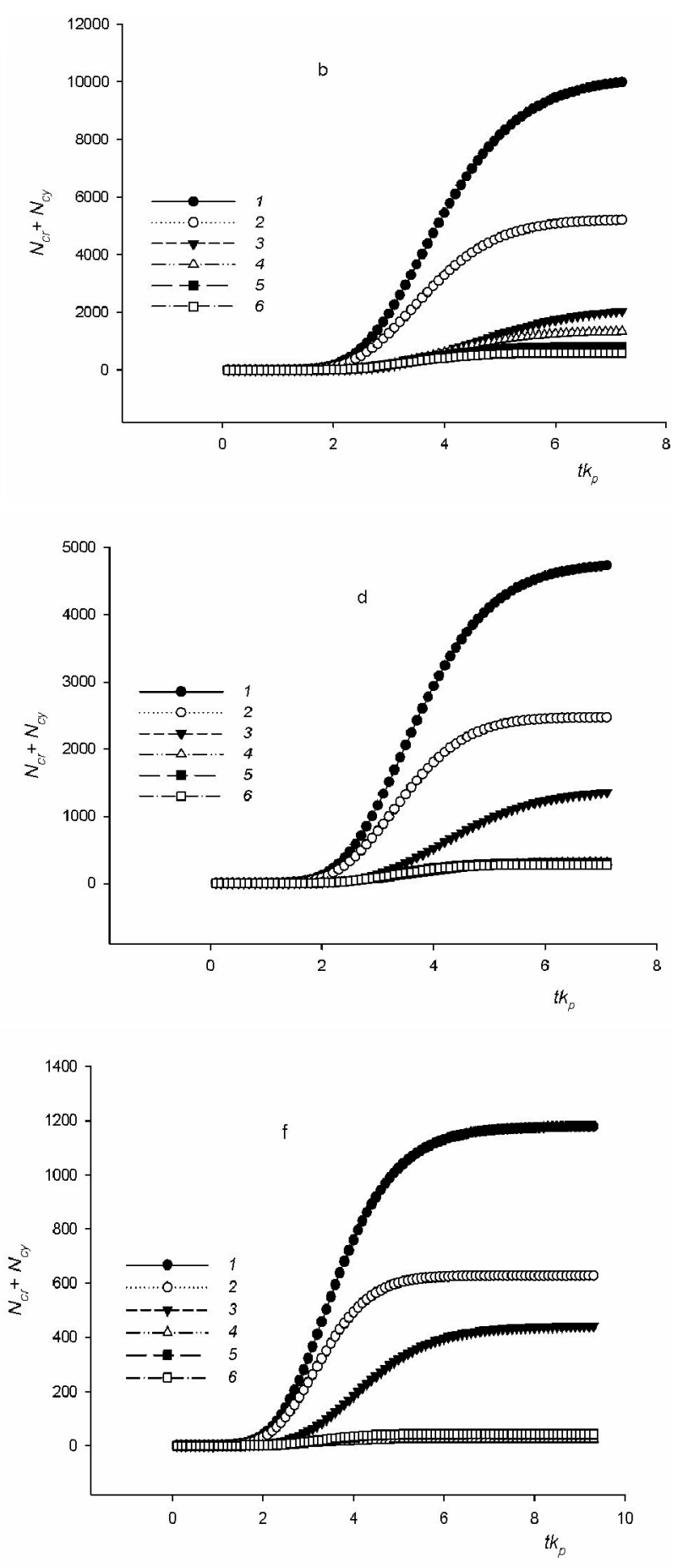

Fig. 5. The impact of the mechanism of reactions R-PG (curve 2), R-R (3), R-R'(4), (R'-R' (5)), R'-PG (6) on the number of cross-links and cycles $\left(N_{c r}+N_{c v}\right.$, curve 1) with $l=1(a), 2(b), 3(c), 4(d), 7(e), 10(f)$, $14(g), 19(h), 25(i), 30(j), 40(k)$ (continued on page 32$)$ 


\section{ИННОВАЦИИ В ХИМИЧЕСКИХ НАУКАХ}
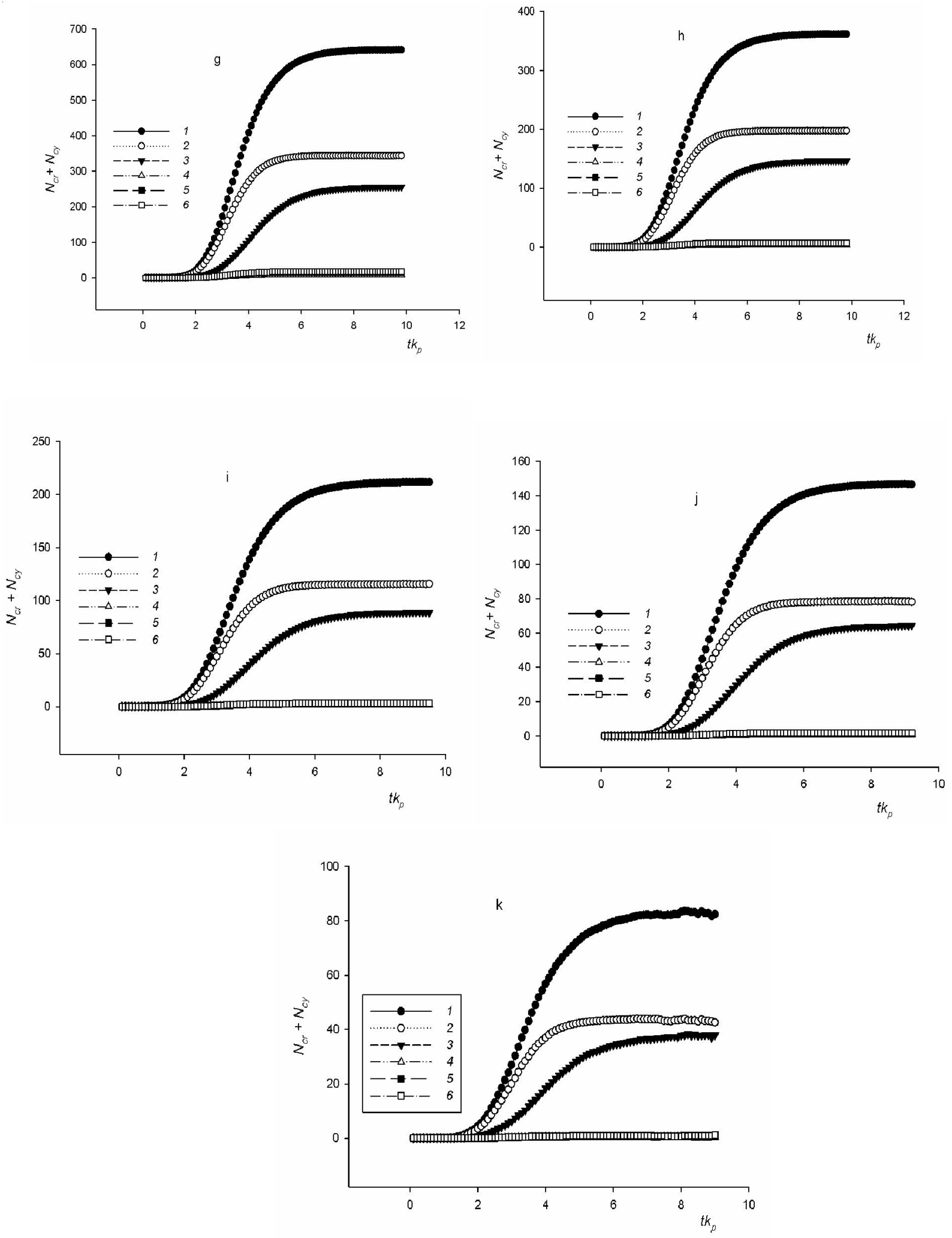

Fig. 5. Ending

We do not separate in this work the share of each of the reactions of cross-linking and cycles formation. On a basis of the competition of these reactions it is obvious that the prevailing reaction is R-PG (Fig. 5, Table 2). Excluding TMF with $l=1$, we see that considered reactions compose a row $N_{R-P G}>N_{R-R}>N_{R-R^{\prime}}>N_{R^{\prime}-R^{\prime}}>N_{R^{\prime}-P G}$ at $l=2-4$; at $l \geq 7$ the row is $N_{R-P G}>N_{R-R}>N_{R^{\prime}-P G}>$ 


\section{ИННОВАЦИИ В ХИМИЧЕСКИХ НАУКАХ}

$>N_{R^{\prime}-R^{\prime}}>N_{R-R^{\prime}}$, reflecting the impact on these reactions the length of TFM molecules. In the case with $l=1$ the row of these reactions is $N_{R-P G}>$ $>N_{R-R^{\prime}}>N_{R-R}>N_{R^{\prime}-R^{\prime}}>N_{R^{\prime}-P G}$ and this dependence reflects the fact that $N_{R^{\prime}}>N_{R}$ at $l=1$ (Table 1).

From comparison of the limiting values of the number of reactions follows that the row $l=2$ -40 the ratio $N_{R-P G} / N_{R-R}$ decreases (relative contribution of reaction R-R grows), and the ratios $N_{R-P G}>N_{R-R^{\prime}}, N_{R-P G}>N_{R^{\prime}-P G}$ and $N_{R-P G}>N_{R^{\prime}-R^{\prime}}$ increase (relative contribution of reaction $R-P G$ decreases) (Table 2). Curves of the dependence of the number of reactions on $t$ are sigma-shaped curves in a row $l \rightarrow(2$-to 40$)$, and at $l=1$ averaged curves have the shape of the curves with acceleration (but in the case of single UTDSE with maximal $P_{n}$ the curves also are sigma-shaped) (Fig. 5). The obtained regularities are unique and are absent in the literature, excluding our works $[4 ; 6 ; 14]$. Our kinetic dependences $\left(N_{c r}+N_{c y}\right)$ (Fig. 5) reflect the character of changes of such topological parameters such as the number of cross-links and the number of cycles in the framework of formation of UTDSE, and the change of $N_{c r}$ and $N_{c y}$ with increasing $P_{n}$ (or the degree of conversion of TFM) allows to understand the nature of their variation during the process of polymerization.

The fall of residual unsaturation in UTDSE (or share of pendant to a carcass of UTDSE double bonds PG) at $l=1$ has the appearance of a smooth drop-down curve (Fig. 6), and with increasing $l$ curves $D(t)$ has a patch sharp drop $D$, turning to the curve of sigma-shaped type the initial part of which is located in the area $D \approx 0.34-0.36$, and the end part located in the field of limit values of $D \approx 0.001$ to 0.018 (Table 2, Fig. 6) with the number of $N_{P G} \approx 1.3 \%$ to 251 . In a series $l \rightarrow(1-15)$ limit values fall, when $l=19$, then rise and then fall again in the row $l \rightarrow(19-40)$ (Table 1, Fig. 6).

Maximum of peak 1 is located in the area $P_{n \text { max }} \approx 3-5$. Peak 2 for $l=1$ is weak (smeared). Obviously, if $l=1 q_{1} / q_{2}=2.51$, then, for example, when $l=30$ the attitude $q_{1} / q_{2}=0.03$, i. e., with
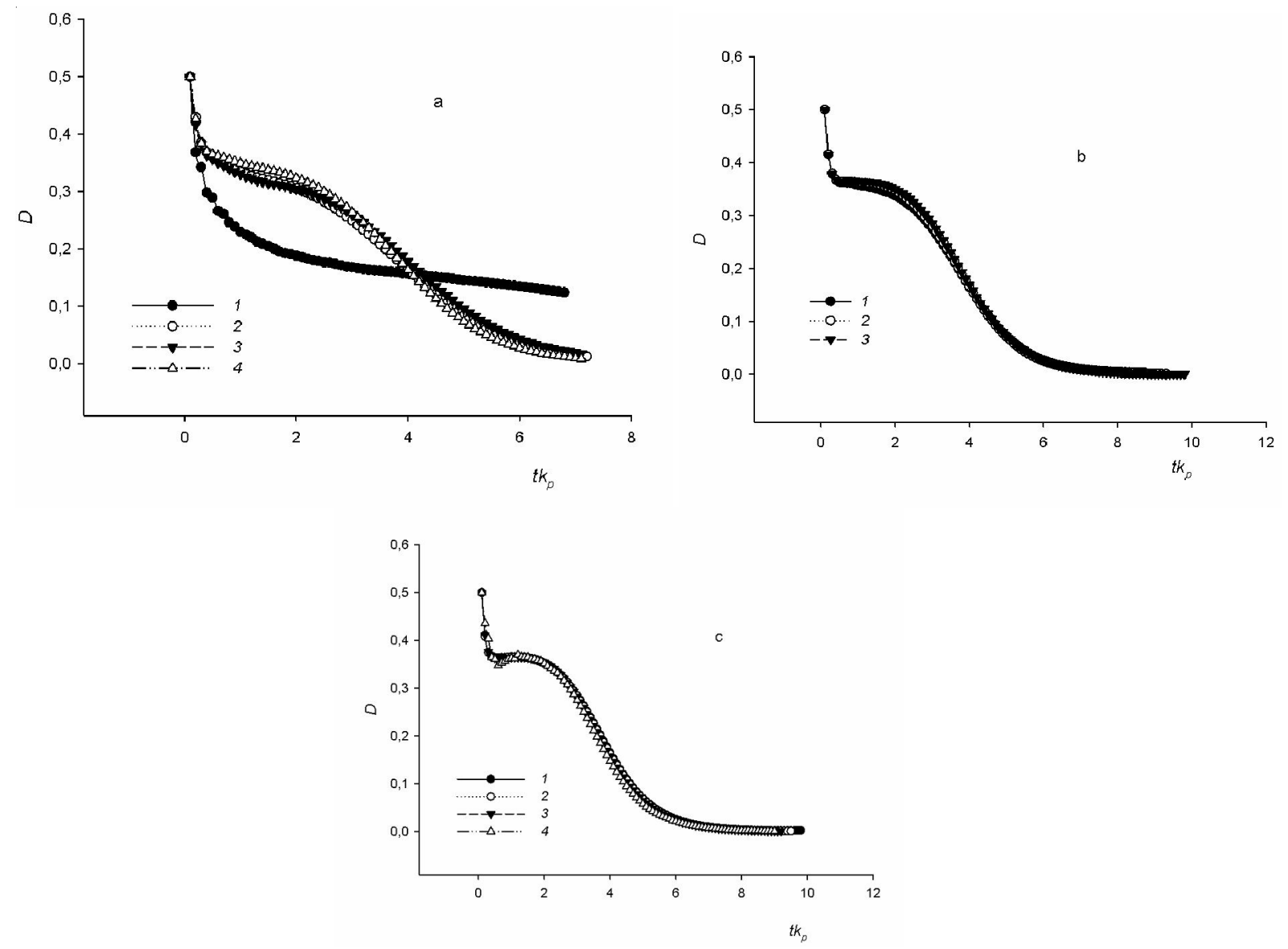

Fig. 6. Kinetic curves of the residual instauration $D$ for UTDSE:

$a-l=1(1), 2(2), 3$ (3), 4 (4); $b-l=7$ (1), 10 (2), 14 (3); $c-l=19$ (1), 25 (2), 30 (3), 40 (4) 
increasing $l$ increases the formation of UTDSE with higher values of $P_{n}$. The formation of a significant proportion of low-molecular UTDSE at $l=1$ confirm the foregoing features of UTDSE formation for TFM with $l=1$. The results of the study GMD of UTDSE are important for solving some practical problems of material science. Note that in [2] was also observed bimodal GMD for the case of three-dimensional polymerization of 1,2dimethacryloiloxyethylene.

During the three-dimensional polymerization of TFM with $l=1$ the coefficient of packing (filling of the reaction volume by structural elements) $k_{\text {pack }}=0.25$, indicating low filling of reaction volume that is correlated with the data of GMDresearch (high share of low-molecular UTDSE). With the elongation of TFM molecules at $l=2-7$ ribs $k_{\text {pack }}$ grows from 0.786 to 0.837 , and when $l>10 k_{\text {pack }}$ again slightly reduced to value $\approx 0.773$ at $l=40$ (Table 1$)$.

\section{Conclusion}

Thus, the performed research allowed identifying a number of the foregoing specific peculiarities and regularities of UTDSE formation which obeyed with increasing of the length of TFM molecules when carrying out the three-dimensional free-radical polymerization of TFM. Namely, we revealed the features of change of the kinetic dependences of polymerization degree $P_{n}$, the number of radicals $N_{R}$ and $N_{R}$, the number of cross-links $N_{c r}$ and cycles $N_{c y}$, share of pendant double bonds $D$ and regularities of changes in these topological parameters of UTDSE depending on the length of TFM molecules. It is formulated: a) the molecular mass of UTDSE sceleton arise because of the reactions of chain growth and topological framing of the sceleton with radicals and cycles is implemented by the reactions of chains initiating, $R-R, R-R^{\prime}, R^{\prime}-R^{\prime}$, $\left.R-P G, R^{\prime}-P G ; \mathrm{b}\right)$ the cross-linking of $j$ mentioned macro-chains is carried out according to the last five reactions; c) structure formation of macro-bodies of three-dimensional polymer proceeds according to the scheme: monomer $\rightarrow$ nanogel (through branched macromolecule to UTDSE) $\rightarrow$ microgel (maltitude of nanogels) $\rightarrow$ macrobody (maltitude of microgels). In accordance with this scheme of macrobodies formation of TDP we have to pay attention to the fact that the stage of formation (synthesis) of UTDSE, assigns to nanochemistry, and the next stage, the stage of formation microgel, assigns to mesoscopic chemistry; d) bimodal grainulometric distribution of UTDSE was discovered, and the ratio of peaks intensity in the fields of low- and highmolecular UTDSE was calculated; e) the authors showed a tendency to increase the occupancy lattices with increasing length of TFM molecules (including due to a change of complementarity of UTDSE with the lattice). The obtained results are useful for understanding the nature of the three-dimensional free-radical polymerization of TFM in the manufacture of industrial products, the development of geltechnology, technology of integrated circuits fabrications, etc.

The authors hope that this work will attract the attention of researchers to this problem and they will create new models and programs for solving this problem, that will deepen understanding of the processes in a three dimensional polymerization of TFM. The authors are skeptical about the creation of experimental techniques to study the formation of UTDSE, at least in the near future.

We emphasize that our series of little-known works $[3-6 ; 14]$ promoted understanding of the problems of kinetics and structure formation in the case of three-dimensional polymers in comparison with the level of knowledge in the 20 th century and in the beginning of 21 st century.

\section{REFERENCES}

1. Berlin A.A., Kefely T.Ya., Korolev G.V. Polyesteracrylates. Moscow, Nauka Publ., 1967.

2. Chiu Y.Y., Lee L.J. J. Polym. Sci.: Part A: Polymer Chemistry, 1995, vol. 33, no. 2, p. 269.

3. Gaisin F.R., Sivergin Yu.M., Usmanov S.M. Monte Carlo Simulation of the Three-dimensional Free-radical Polymerization of Tetra-functional Monomers (On Lattices of Different Dimensions and Geometry as a Part of the Formation of a Single ThreeDimensional Structural Element). Moscow, Altair Publ., 2010, Part 2.

4. Gaisin F.R., Sivergin Yu.M., Usmanov S.M. Monte Carlo Simulation of the Three-dimensional Free-radical Polymerization of Tetra-functional 


\section{ИННОВАЦИИ В ХИМИЧЕСКИХ НАУКАХ}

Monomers (On Lattices of Different Dimensions and Geometry as a Part of the Formation of a Single ThreeDimensional Structural Element). Moscow, Altair Publ., 2010, Part 3.

5. Gaisin F.R., Sivergin Yu.M., Usmanov S.M. Monte Carlo Simulation of the Three-dimensional Free-radical Polymerization of Tetra-functional Monomers (On Lattices of Different Dimensions and Geometry as a Part of the Formation of a Single ThreeDimensional Structural Element). Moscow, Altair Publ., 2010, Part 4.

6. Gaisin F.R., Sivergin Yu.M., Usmanov S.M. Monte Carlo Simulation of the Three-dimensional Free-radical Polymerization of Tetra-functional Monomers (On Lattices of Different Dimensions and Geometry as a Part of the Formation of a Single ThreeDimensional Structural Element). Ufa, Gilem Publ., 2009.
7. Pavlova O.V., Kireeva S.M., Sivergin Yu.M. Acta Polymer, 1992, vol. 43, p. 114. (in Russian).

8. Pavlova O.V., Kireeva S.M., Sivergin Yu.M. Polymer Science, 1987, vol. 29A, p. 1777. (in Russian).

9. Pavlova O.V., Kireeva S.M., Sivergin Yu.M. Vysokomol. Soed., 1990, vol. 32A, p. 1256. (in Russian).

10. Sivergin Yu.M., Perniks R.Ya., Kireeva S.M. Polycarbonatmethakrylates. Riga, Zinatne, 1988.

11. Sivergin Yu.M., Stankevitch I.V. Chemical Physics, 2006, vol. 25, no 1, p. 89. (in Russian).

12. Sivergin Yu.M., Stankevitch I.V. Plastics, 2005, no. 5, p. 35. (in Russian).

13. Sivergin Yu.M., Usmanov S.M. Synthesis and Properties of Oligoestermethacrylates. Moscow, Khimiya Publ., 2000.

14. Usmanov S.M., Gaisin F.R., Sivergin Yu.M. Russian plastics technology journal, 2005, no. 8, p. 19. (in Russian).

\section{МОДЕЛИРОВАНИЕ МЕТОДОМ МОНТЕ-КАРЛО ТРЕХМЕРНОЙ СВОБОДНО-РАДИКАЛЬНОЙ ПОЛИМЕРИЗАЦИИ ТЕТРАФУНКЦИОНАЛЬНЫХ МОНОМЕРОВ}

\section{Юрий Михайлович Сивергин}

Доктор химических наук, профессор,

Институг химической физики им. Н.Н. Семенова РАН

library@chph.ras.ru

ул. Косыгина, 4, 119991 г. Москва, Российская Федерация

\section{Салават Мударисович Усманов}

Доктор физико-математических наук, профессор, директор Бирского филиала Башкирского государственного университета academy@birsk.ru ул. Интернациональная, 10, 452453 г. Бирск, Российская Федерация

\section{Фаниль Рафакович Гайсин}

Кандидат физико-математических наук,

доцент кафедры математического моделирования, информационных систем и экономики, Бирский филиал Башкирского государственного университета academy@birsk.ru ул. Интернациональная, 10, 452453 г. Бирск, Российская Федерация

\section{Александр Львович Коварский}

Заслуженный деятель науки РФ, доктор химических наук, профессор, руководитель Центра магнитной спектроскопии, Институг биохимической физики им. Н.М. Эмануэля РАН library@chph.ras.ru ул. Косыгина, 4, 119991 г. Москва, Российская Федерация 


\section{ИННОВАЦИИ В ХИМИЧЕСКИХ НАУКАХ}

Аннотация. В работе представлены результаты моделирования методом Монте-Карло кинетики трехмерной свободно-радикальной полимеризации тетрафункциональных мономеров (ПМФ), которые были получены в рамках создания единого трехмерного структурного элемента (UTDSE) и структура которых формировалась на простой кубической решетке в зависимости от длины $l$ молекул тетрафункциональных мономеров ( $l=1$ до 40 ребер решетки). Были выявлены особенности кинетики изменения таких параметров, как степень полимеризации $P_{n}$ UTDSE, количество радикалов, количество сшивок и циклов и другие характеристики. Было установлено, что UTDSE характеризуются низким уровнем $P_{n}$, и было дано объяснение этого явления.

Ключевые слова: математическое моделирование, метод Монте-Карло, полимеризация, тетрафункциональные мономеры, длина молекул. 